\title{
Article \\ Optimization of a MOF Blended with Modified Polyimide Membrane for High-Performance Gas Separation
}

\author{
Yushu Zhang ${ }^{1}$, Hongge Jia ${ }^{1, *}$, Qingji Wang ${ }^{2}$, Wenqiang Ma ${ }^{1}$, Guoxing Yang ${ }^{3}$, Shuangping Xu ${ }^{1, *}$, Shaobin Li ${ }^{1}$, \\ Guiming Su ${ }^{4}$, Yanqing $\mathrm{Qu}{ }^{1}$, Mingyu Zhang ${ }^{1}$ and Pengfei Jiang ${ }^{1}$ \\ 1 Heilongiiang Provinces Key Laboratory of Polymeric Composite Materials, \\ Department of Chemical and Chemical Engineering, Qiqihar University, Wenhua Street, Qiqihar 161006, \\ China; 18204667530@163.com (Y.Z.); mfeather7@163.com (W.M.); qqhrlsb1022@126.com (S.L.); \\ vipquyanqing@163.com (Y.Q.); zhangmingyuno1@163.com (M.Z.); jpf848185@163.com (P.J.) \\ 2 CNPC Reasearch Institute of Safety \& Environment Technology, Changping District, Beijing 102249, China; \\ wangqingji@petroChina.com.cn \\ 3 Synthetic Resin Laboratory, Daqing Petrochemical Research Center, Petrochemical Research Institute, No. 2, \\ Chengxiang Road, Wolitun, Longfeng District, Daqing 163714, China; ygx459@petrochina.com.cn \\ 4 Institute of Advanced Technology, Heilongjiang Academy of Sciences, No. 52, Renhe Street, Nangang District, \\ Harbin 150009, China; suguim@163.com \\ * Correspondence: jiahongge@qqhru.edu.cn (H.J.); xshp_1979_1999@163.com (S.X.)
}

check for

updates

Citation: Zhang, Y.; Jia, H.; Wang, Q.; Ma, W.; Yang, G.; Xu, S.; Li, S.; Su, G.; Qu, Y.; Zhang, M.; et al. Optimization of a MOF Blended with Modified

Polyimide Membrane for

High-Performance Gas Separation.

Membranes 2022, 12, 34 .

https://doi.org/10.3390/

membranes12010034

Academic Editor: Rahul Singh

Received: 26 November 2021

Accepted: 22 December 2021

Published: 27 December 2021

Publisher's Note: MDPI stays neutral with regard to jurisdictional claims in published maps and institutional affiliations.

Copyright: (c) 2021 by the authors. Licensee MDPI, Basel, Switzerland. This article is an open access article distributed under the terms and conditions of the Creative Commons Attribution (CC BY) license (https:// creativecommons.org/licenses/by/ $4.0 /)$.

\begin{abstract}
The preparation, characterization and gas separation properties of mixed matrix membranes (MMMs) were obtained from polyimide capped with ionic liquid and blended with metal-organic frameworks (MOFs). The synthesized MOF was amine functionalized to produce $\mathrm{UiO}-66-\mathrm{NH}_{2}$, and its amino group has a higher affinity for $\mathrm{CO}_{2}$. Mixed matrix membranes exhibited good membrane forming ability, heat resistance and mechanical properties. The polyimide membrane exclusively capped by ionic liquid exhibited good permselectivity of 74.1 for $\mathrm{CO}_{2} / \mathrm{CH}_{4}$, which was 6.2 times that of the pure polyimide membrane. It is worth noting that $\mathrm{MMM}$ blended with UiO-66- $\mathrm{NH}_{2}$ demonstrated the highest ideal selectivity for $\mathrm{CO}_{2} / \mathrm{CH}_{4}$ (95.1) with a $\mathrm{CO}_{2}$ permeability of 7.61 Barrer, which is close to the 2008 Robeson upper bound. The addition of UiO-66- $\mathrm{NH}_{2}$ and ionic liquid enhanced the permselectivity of MMMs, which may be one of the promising technologies for high performance $\mathrm{CO}_{2} / \mathrm{CH}_{4}$ gas separation.
\end{abstract}

Keywords: mixed matrix membrane; metal-organic frameworks; polyimide; gas separation

\section{Introduction}

Concerns about global warming have brought unprecedented public attention on the issue of carbon emissions [1-4]. As a result, an effective technique for separating the carbon dioxide from a mixture is required. Gas separation membrane technology is an effective method. The objective that researchers have been trying to achieve is a membrane material with high permeability and high selectivity. While gas separation membranes have advanced significantly, numerous gas separation membranes with excellent characteristics have emerged, such as polymer membranes [5]; metal-organic framework membrane (MOF) [6-8]; carbon membranes and zeolite membranes [9,10]; and various mixed matrix membranes (MMM) [11-13]. Polymer membranes are the most important commercial membranes for gas separation due to their advantages, which include the ease of membrane formation and low cost. However, polymer membranes are usually limited in their equilibrium relationship between selectivity and permeability, which makes it difficult to achieve both simultaneously $[14,15]$. Robeson applied extensive experimental data to demonstrate the inverse relationship between selectivity and permeability of polymer membranes and defined the Robeson upper bound $[16,17]$. For the past two decades, the focus of separation membrane research has been on how to exceed the upper bound. Common mem- 
brane modification methods include thermal rearrangement modification [18,19]; grafting modification [20]; and mixed matrix membranes, etc.

Metal organic framework materials (MOFs) are a new type of crystalline porous materials with tunable structure and function, which are formed by coordinated self-assembly of metal clusters/ions and ligands [21-23]. Metal-organic skeleton materials are widely used in various industries, including as catalysts; liquid phase separation; and hydrogen storage and gas separation due to their high porosity and good chemical stability. However, with industrially produced tunable separation membranes with excellent properties of metal-organic skeletal materials, it is necessary to focus on how to simultaneously produce separation membranes with high selectivity; high permeability; high mechanical strength; and stability. Bernabe et al. [24,25] presented a modified polyimide membrane using microporous aluminum fumarate (A520) as the filler to improve permselectivity for $\mathrm{CO}_{2} / \mathrm{N}_{2}$ and $\mathrm{O}_{2} / \mathrm{N}_{2}$. When compared to the pure PI membrane, these membranes have improved $\mathrm{CO}_{2}$ permeability of $38.5 \%$ and $\mathrm{O}_{2}$ permeability of $357.8 \%$. ZIF-302 (zeolitic imidazolate framework) particles were added into a polyimide matrix to form self-consistent MMMs [12]. MMMs exhibited a 6.05-fold increase in $\mathrm{CO}_{2}$ permeance compared with pure dense MMM. Liu et al. [26] described a branched polyethyleneimine (PEI) functionalized UiO-66 as the filler in a 6FDA-ODA polyimide mixed matrix membrane. The MMM with $15 \mathrm{wt} \%$ loading content has $\mathrm{CO}_{2} / \mathrm{CH}_{4}$ selectivity of 56.49 .

However, when the metal-organic framework is blended with the polymer matrix, their inadequate compatibility often results in inhomogeneous dispersion [27]. Ionic liquids (ILs) are characterized by high compatibility and good thermal stability [28]. As green solvents, ionic liquids have been considered as a promising substance for $\mathrm{CO}_{2}$ separation. Zhang et al. [29] described a supported ionic liquid membrane (SILM) that achieved high $\mathrm{CO}_{2}$ permeability and selectivity for $\mathrm{CO}_{2} / \mathrm{N}_{2}$ (2540 Barrers and 127 , respectively). A new class of CA (cellulose acetate)-derived poly(ionic liquid) as a thin film composite membrane for $\mathrm{CO}_{2}$ separation was reported by Nikolaeva et al. [30]. Incorporation of ionic moiety into the polymer structure resulted in a considerable threefold increase in $\mathrm{CO}_{2}$ permeability compared to pure CA, with only a slight decrease in selectivity.

In the present article, we first report on a simple method for preparing a series of membranes in which polyimide is capped with ionic liquid, and blended with $\mathrm{UiO}-66-\mathrm{NH}_{2}$. UiO-66- $\mathrm{NH}_{2}$ is a metal-organic framework material composed of metal zirconium ions and 2-aminoterephthalic acid as ligands connected by metal bonds, which is often used as a filler to enhance the physicochemical properties of polymers. The amine group on UiO-66- $\mathrm{NH}_{2}$ particles can strengthen the affinity for $\mathrm{CO}_{2}$ and, hence, increase permeability. The introduction of ionic liquids helps to improve interfacial compatibility between the substrate and the MOF. Moreover, the study found that the polyimide capped by ionic liquid improved gas separation performance for the $\mathrm{CO}_{2} / \mathrm{CH}_{4}$ gas pair. When the ionic liquid capped polyimide was blended with $\mathrm{MOF}$, permeability and separation of membranes were both enhanced. This provides a facile solution to overcome the limitation of the "trade-off."

\section{Materials and Methods}

\subsection{Materials}

$\mathrm{ZrCl}_{4}(99 \%) ;$-aminoterephthalic acid $\left(\mathrm{NH}_{2}\right.$-BDC) $(98 \%) ; 3,3^{\prime}, 4,4^{\prime}$-Benzophenonetetracarboxylic dianhydride (BTDA) (98\%); and 4,4'-Diaminodiphenyl ether (ODA) (98\%) were purchased from Aladdin (Shanghai, China). 1-carboxyethyl-3-methylimidazolium chlorine (99\%) was purchased from Lanzhou Institute of Chemical Physics (Lanzhou, China). N,Ndimethylformamide (DMF) and methanol were purchased from Tianjin Kemiou Chemical Reagent Co., Ltd. (Tianjin, China).

\subsection{Preparation of $\mathrm{UiO}-66-\mathrm{NH}_{2}$}

UiO-66- $\mathrm{NH}_{2}$ was synthesized according to a published procedure [31], with some improvements. Briefly, $\mathrm{ZrCl}_{4}(0.87 \mathrm{~mol}, 2.01 \mathrm{~g})$ and 2 -aminoterephthalic acid $(0.87 \mathrm{~mol}, 1.56 \mathrm{~g})$ were mixed with $90 \mathrm{~mL}$ DMF in a $250 \mathrm{~mL}$ flask. The mixture was heated by Microwave 
chemical reactor with $800 \mathrm{~W}$ for $30 \mathrm{~min}$. The solution was centrifuged and washed with DMF and methanol to exchange solvents. The obtained solids were evaporated in a vacuum oven at $110^{\circ} \mathrm{C}$ overnight [32].

\subsection{Synthesis of PI-IL/UiO-66-NH $\mathrm{H}_{2}$ Membranes}

As shown in Scheme 1, PI-IL membranes were synthesized by polycondensation reaction. BTDA $(1.1 \mathrm{~mol}, 1.4 \mathrm{~g})$ and ODAs $(1.0 \mathrm{~mol}, 0.60 \mathrm{~g})$ were dissolved in DMF $(3 \mathrm{~mL})$ to form a polyamic acid (PAA) solution for $4 \mathrm{~h}$ at $20{ }^{\circ} \mathrm{C}$. Ionic liquid 1-carboxyethyl-3methylimidazolium hexafluorophosphate $(0.10 \mathrm{mmol}, 0.020 \mathrm{~g})$ was dissolved in DMF solution, then the solution was added into polyamic acid solution. The solution was stirred for $6 \mathrm{~h}$ to react sufficiently. After that, $\mathrm{UiO}-66-\mathrm{NH}_{2}(1 \mathrm{wt} \%, 2 \mathrm{wt} \%, 3 \mathrm{wt} \%, 4 \mathrm{wt} \%$ and $5 \mathrm{wt} \%$ ) was dispersed in DMF and sonicated for $15 \mathrm{~min}$, then the dissolved UiO-66- $\mathrm{NH}_{2}$ solution was mixed with the PI-IL solution and stirred for $24 \mathrm{~h}$. After standing for $2 \mathrm{~h}$ to remove bubbles (no sedimentation of MOF due to the uniform dispersion in the casting solution [33]), the mixed solution was casted in a clean glass dish and dried at $80-280{ }^{\circ} \mathrm{C}$ for $10 \mathrm{~h}$ in order to obtain the mixed matrix membrane. The compositions of the synthesized membranes are listed in Table 1.

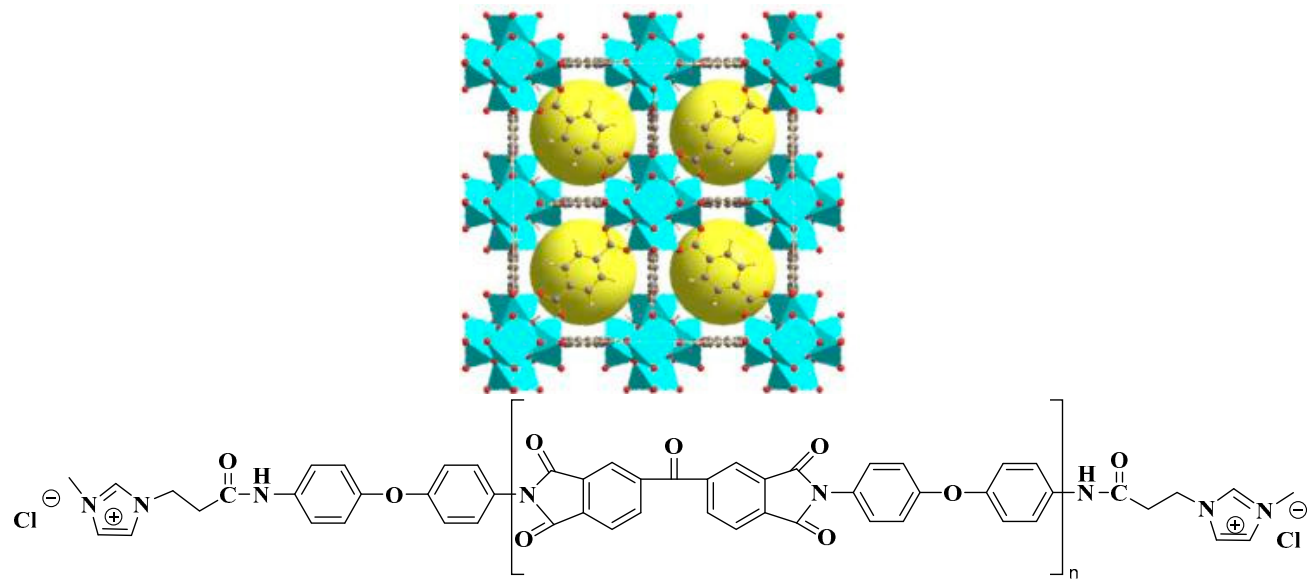

Scheme 1. Structure of UiO-66- $\mathrm{NH}_{2}$ and PI-IL.

Table 1. Compositions of synthesized membrane.

\begin{tabular}{|c|c|}
\hline Membrane & Composition \\
\hline Pure PI & BTDA + ODA \\
\hline PI-IL & $\mathrm{BTDA}+\mathrm{ODA}+\mathrm{IL}$ \\
\hline PI-IL/1\% MOF & $1 \%$ UiO-66-NH $\mathrm{NH}_{2}+99 \%$ PI-IL \\
\hline PI-IL $/ 2 \%$ MOF & $2 \% \mathrm{UiO}-66-\mathrm{NH}_{2}+98 \%$ PI-IL \\
\hline PI-IL/3\% MOF & $3 \%$ UiO-66-NH $+97 \%$ PI-IL \\
\hline PI-IL/4\% MOF & $4 \%$ UiO-66-NH $-96 \%$ PI-IL \\
\hline PI-IL/5\% MOF & $5 \%$ UiO-66-NH $-95 \%$ PI-IL \\
\hline
\end{tabular}

\subsection{Characterization of the Materials}

The crystal structure of the sample was determined by using X-ray diffraction (XRD) (D8 advanced diffractometer, Bruker AXS, Karlsruhe, Germany). The morphology of the MOF and cross sections of the membranes were observed by scanning electron microscope (SEM) (S-3400, Hitachi, Tokyo, Japan). Fourier Transform Infrared Spectroscopy (FT-IR) (Spectrum Two, PE company, Los Angeles, CA, USA) was used to determine the chemical structure of the samples. The nitrogen adsorption-desorption isotherm of the sample was measured with an adsorption instrument (ASAP 2020 Plus HD88, Micromeritics, Norcross, GA, USA), and the test was carried out after degassing at $120{ }^{\circ} \mathrm{C}$ for $12 \mathrm{~h}(80 \mathrm{mg}$ of the sample). The particles were analyzed according to their specific surface area and pore size 
distribution at $77 \mathrm{~K}$. A thermogravimetry analyzer (TGA 8000, Perkin Elmer, Waltham, MA, USA) was used for a thermal performance test, the flow rate of $\mathrm{N}_{2}$ was $40 \mathrm{~mL} / \mathrm{min}$ and the heating rate was $5^{\circ} \mathrm{C} / \mathrm{min}$.

\subsection{Gas Permeation Measurements of Membranes}

The mixed gas permeability and selectivity of the membranes were measured at $34{ }^{\circ} \mathrm{C}$ using a GTR-11MH gas permeability analyzer (GTR Tec Corporation, Uji, Kyoto). The test area was $0.785 \mathrm{~cm}^{2}$, the test pressure is maintained at $49 \mathrm{KPa}$, the test gas is a 1:1 mixture of $\mathrm{CO}_{2}$ and $\mathrm{CH}_{4}$, the carrier gas is $\mathrm{H}_{2}$ and the pressure is $0.1 \mathrm{MPa}$ for testing. The gas permeability coefficient was calculated using Formula (1).

The diffusion coefficients (D) and the solubility coefficients (S) were calculated by using Equations (2) and (3) [34]:

$$
\begin{gathered}
P=\frac{q \times K \times L}{a \times p \times t}\left(\mathrm{~mL} \cdot \mathrm{cm} \cdot \mathrm{cm}^{-2} \cdot \mathrm{s}^{-1} \cdot \mathrm{cmHg}^{-1}\right) \\
\mathrm{D}=\frac{L^{2}}{6 T} \\
\mathrm{~S}=\frac{P}{D}
\end{gathered}
$$

where $q$ is the gas permeation measured by the instrument, $\mathrm{mL} ; K$ is the auxiliary positive coefficient of the instrument, with a fixed value of $1.25 ; L(\mathrm{~cm})$ is the thickness of the gas separation membrane; $a$ is the permeation area in the instrument (set at $\left.0.785 \mathrm{~cm}^{2}\right) ; p(\mathrm{cmHg})$ is the pressure while the instrument is testing; and $t(\mathrm{~s})$ is the time it takes for the instrument to measure the gas separation membrane, which was determined by the specific operation of the operator.

\section{Results}

\subsection{Fabrication and Characterization of $\mathrm{UiO}-66-\mathrm{NH}_{2}$}

Microwave heating is an effective tool in organic chemistry synthesis, but it has also recently been used in the synthesis of inorganic and inorganic/organic materials. In addition, the conversion of microwave radiation to heat is often efficient and homogeneous throughout the sample, which reduces energy consumption and the necessity for heat transfer in the mixture [35]. For the reasons stated above, we employed microsynthesis technology to prepare $\mathrm{UiO}-66-\mathrm{NH}_{2}$, and the reaction time decreased to $30 \mathrm{~min}$, which presented a 47-fold reduction in reaction time compared to the conventional method. The yield of MOF using microwave synthesis was 50\%, while the yield of MOF using traditional solvothermal process was $35 \%$. The crystal structure of UiO-66- $\mathrm{NH}_{2}$ was characterized by XRD. In Figure $1 \mathrm{a}$, the powder X-ray diffraction pattern of the synthesized UiO-66- $\mathrm{NH}_{2}$ shows excellent agreement with the simulated diffraction pattern. All of the diffraction peaks of the micro-assisted synthesized MOFs correlate well with the simulated spectrum [31,36]. Figure $1 \mathrm{~b}$ depicts the morphology of $\mathrm{UiO}-66-\mathrm{NH}_{2}$, which has a particle size of $100-200 \mathrm{~nm}$ and an ortho-octahedral structure, and exhibited good crystal shape regularity, particle size uniformity and crystal perfection. The nitrogen adsorption-desorption isotherm and pore size distribution curve of $\mathrm{UiO}-66-\mathrm{NH}_{2}$ are presented in Figure 1c. UiO-66- $\mathrm{NH}_{2}$ follows Type 1 isotherm, which is indicative of microporosity. The surface area of the BrunauerEmmett-Teller (BET) surface area was $813.25 \mathrm{~m}^{2} / \mathrm{g}$, and the pore volume was $0.44 \mathrm{~cm}^{3} / \mathrm{g}$, which can contribute to gas permeability. The BET area of micro-synthesized MOF is lower than that of conventional solvothermal process, while the pore is bigger. This phenomenon may be due to fewer defects; thus, the specific surface area is smaller [35]. The results of XRD, SEM and $\mathrm{N}_{2}$ adsorption-desorption isotherm confirmed the successful preparation of UiO-66- $\mathrm{NH}_{2}$ nanoparticles using microwave-assisted synthesis. 

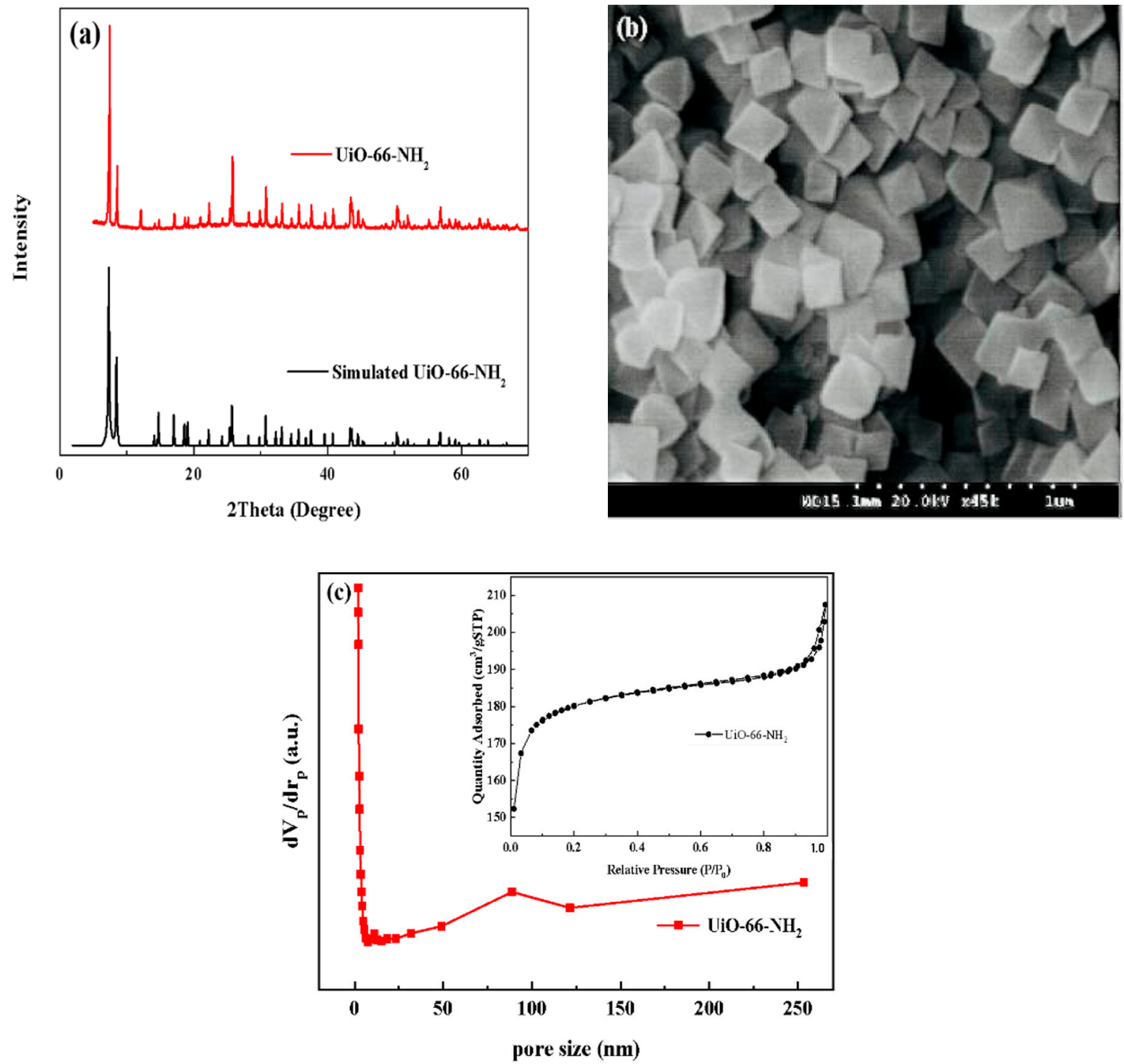

Figure 1. (a) XRD patterns of synthesized $\mathrm{UiO}-66-\mathrm{NH}_{2}$, (b) $\mathrm{SEM}$ image of synthesized $\mathrm{UiO}-66-\mathrm{NH}_{2}$, (c) nitrogen adsorption isotherm $(77 \mathrm{~K})$ and pore size distributions of $\mathrm{UiO}-66-\mathrm{NH}_{2}$.

\subsection{Characterization of $M M M s$}

In order to verify whether PI is fully imidized, the FT-IR spectra of PAA and PI are shown in Figure 2. The peak at $1665 \mathrm{~cm}^{-1}$ is the absorption vibration peak of $-\mathrm{NH}$ on the polyimide amide group, which indicated the formation of PAA. For the PI spectrum, this peak becomes weaker, indicating that PAA has been completely imidized to form PI. After imidization, the stretching vibration peak of $\mathrm{C}-\mathrm{N}$ in polyimide is at $1238 \mathrm{~cm}^{-1}$, and the absorption peak of $\mathrm{C}=\mathrm{O}$ in $1729 \mathrm{~cm}^{-1}$ was weakened, which proves that polyimide was formed [37]. Before SEM characterization, the membrane samples were brittled with liquid nitrogen, and the broken side was marked. As shown in Figure 3, the aggregation phase of IL is not visible in cross-section electron microscopy, which proves that the ionic liquids are not comingled in the matrix membrane but capped into polyimide. The bulky parts are the polyimide-ionic liquid matrices. The SEM images of the PI-IL/3\% MOF membrane revealed that $\mathrm{UiO}-66-\mathrm{NH}_{2}$ particles are well dispersed in the matrix and there is no significant agglomeration of the filler. It can be observed from Figure 3 that the number of $\mathrm{UiO}-66-\mathrm{NH}_{2}$ particles in the electron micrographs increases as loading content increases. The size of the nanoparticles in the membranes is $200-300 \mathrm{~nm}$, which is comparable to and slightly larger than the size of pure $\mathrm{UiO}-66-\mathrm{NH}_{2}$. The particles are wrapped in a PI matrix, and the interface is blurred, demonstrating that membrane compatibility has improved. This is in accordance with the experimental theory, as the viscosity of the polyimide casting solution is very high, and the MOF particles added to it are enveloped by the casting solution. Consequently, the 
particle pattern in the cross-sectional electron micrographs of the film is inclined to be round, which proves that the MOF is successfully mixed into the matrix membrane. As shown in Figure S2 (in Supplementary Materials), by applying surface scanning electron microscope in mixed matrix membranes, all membranes are basically uniformly dispersed, and there was only a very small amount of agglomeration of MOF.

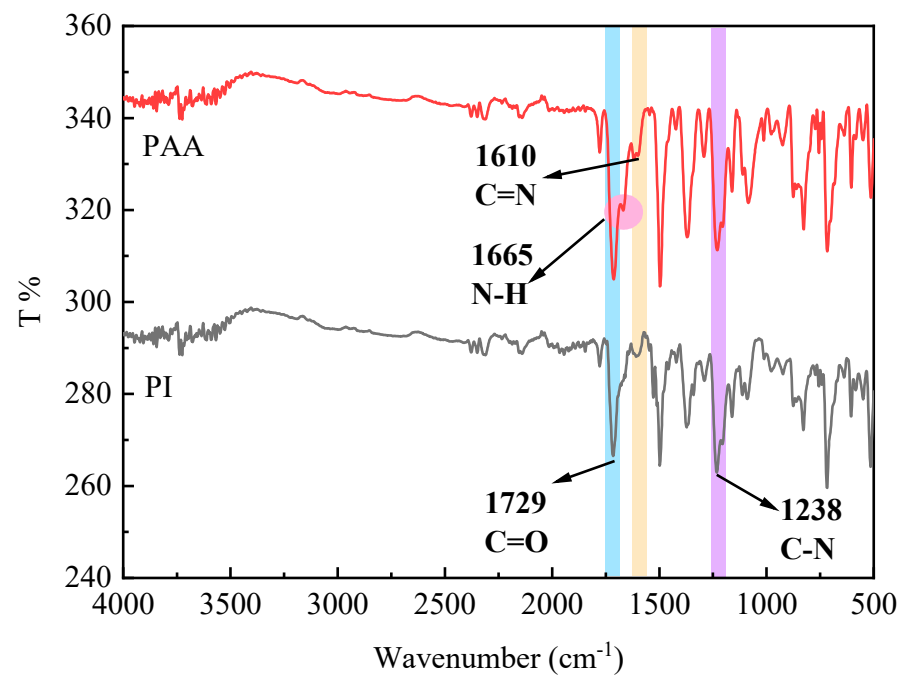

Figure 2. FT-IR spectrum of PAA and PI.
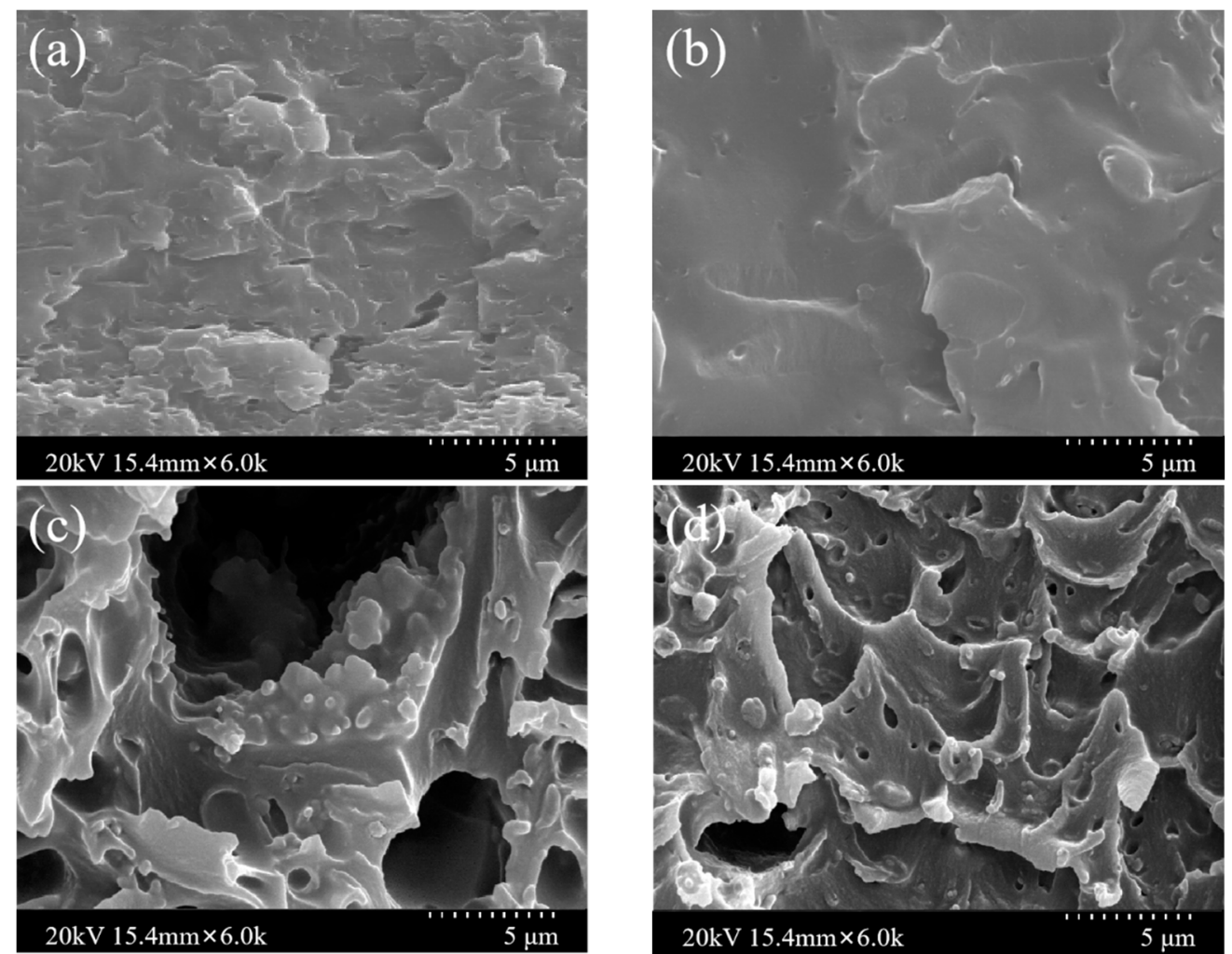

Figure 3. Cont. 

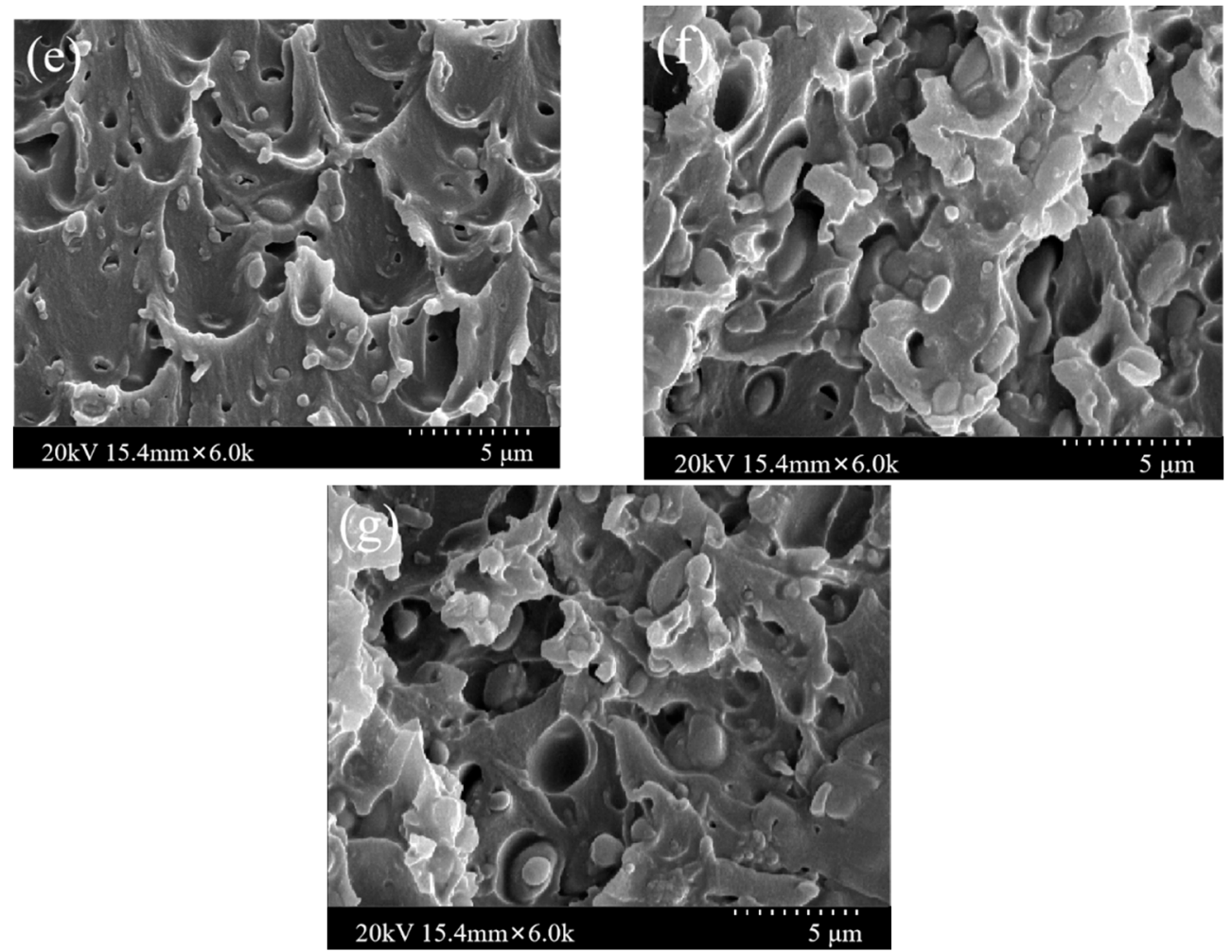

Figure 3. SEM images of the cross-section of pure PI (a), PI-IL (b) and PI-IL/1-5\%MOF mixed matrix membranes $(\mathbf{c}-\mathbf{g})$.

\subsection{Mechanical Properties of Membranes}

As shown in Table 2, the yield strength ( $\sigma s)$; elongation at break ( $\varepsilon b)$; tensile strength (TS); and modulus of elasticity (E) of the ionic liquid-terminated polyimide membranes were measured from the tensile strength test. Figure 4 is a visualization of the trends in the mechanical properties and corresponds to the folded line point diagram of tensile strength and elongation at the break of the membranes.

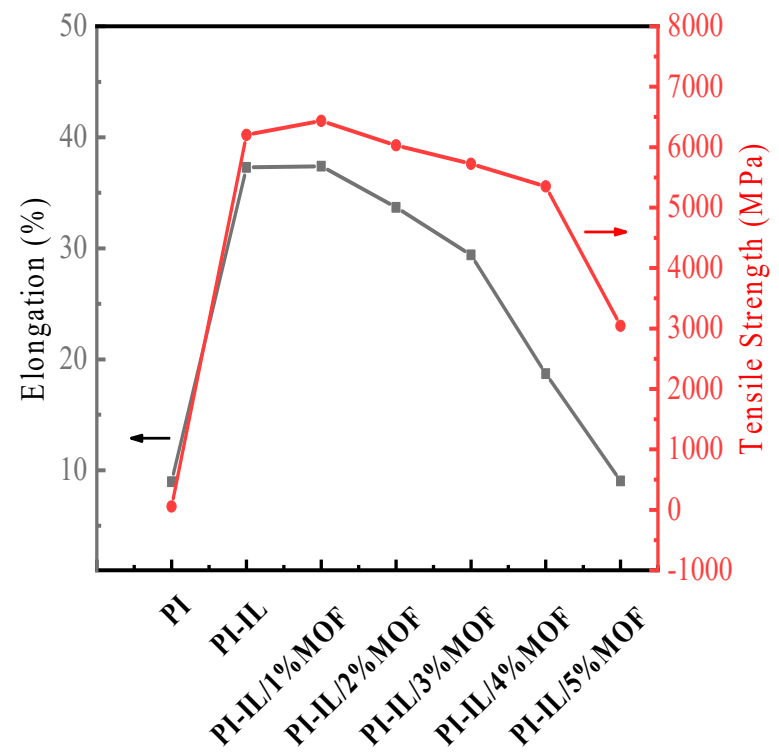

Figure 4. Mechanical properties of PI (PI), PI-IL (PI-IL) and PI-IL/x\% (1\%, 2\%, 3\%, 4\% and 5\%) MOF membranes. 
Table 2. Mechanical properties of PI-IL/x\%MOF membranes ${ }^{\mathrm{a}}$.

\begin{tabular}{ccccc}
\hline Sample & Yield Strength (MPa) & Elongation at Break (\%) & Tensile Strength (MPa) & Modulus of Elasticity (MPa) \\
\hline PI & $0.61 \pm 0.03$ & $8.96 \pm 0.09$ & $53.6 \pm 0.25$ & $59.2 \pm 0.21$ \\
PI-IL & $54.4 \pm 0.23$ & $37.3 \pm 0.16$ & $6203 \pm 2.13$ & $177 \pm 0.67$ \\
PI-IL-1\% MOF & $55.6 \pm 0.27$ & $37.4 \pm 0.21$ & $6434 \pm 2.34$ & $183 \pm 0.78$ \\
PI-IL-2\% MOF & $52.4 \pm 0.56$ & $33.7 \pm 0.12$ & $6031 \pm 2.54$ & $174 \pm 0.63$ \\
PI-IL-3\% MOF & $49.4 \pm 0.41$ & $29.4 \pm 0.14$ & $5724 \pm 2.16$ & $143 \pm 0.58$ \\
PI-IL-4\% MOF & $46.5 \pm 0.45$ & $18.7 \pm 0.15$ & $5352 \pm 2.11$ & $105 \pm 0.46$ \\
PI-IL-5\% MOF & $34.5 \pm 0.48$ & $9.04 \pm 0.08$ & $3042 \pm 1.51$ & $98.4 \pm 0.33$ \\
\hline
\end{tabular}

Note: ${ }^{a}$ Tested at $5.00 \mathrm{~mm} / \mathrm{min}$ speed. The standard spline had a length of $40 \mathrm{~mm}$ and a width of $10 \mathrm{~mm}$

The ionic liquid-capped polyimide membrane has better mechanical properties than a pure polyimide membrane, with the elongation of the break increasing from $8.96 \%$ to $37.3 \%$ and tensile strength increasing from 53.6 MPa to $6203 \mathrm{MPa}$. When IL was added to cover the end groups of the polyimide matrix, the unique electronic structure of the ionic liquid influenced the orientation of the molecular chains and increased the orientation. Simultaneously, it restricted the mobility of polyimide chain segments, increasing the degree of build up and enhancing intermolecular interactions, which resulted in its increased mechanical strength.

The tensile strength and elongation at the break of PI-IL $/ 1 \%$ MOF reached a maximum of $37.4 \%$ and $6434 \mathrm{MPa}$, respectively. It may be due to the large interfacial interaction between the doped $\mathrm{UiO}-66-\mathrm{NH}_{2}$ and the substrate polyimide. With the increase in MOF content, the tensile strength and elongation at the break of the membranes tended to decrease; this tendency may be due to the rigid structure of MOF, which makes the original excellent mechanical properties slightly inferior but still maintains good mechanical properties. This shows that all the produced mixed matrix membranes have good mechanical properties and completely fulfill the requirements under which the membranes may be used.

\subsection{Thermal Properties of the Membranes}

A TGA measurement in a $\mathrm{N}_{2}$ atmosphere was used to determine the thermal stability of PI, PI-IL and PI-IL $/ \mathrm{x} \%$ MOF membranes. The TGA curve of MOF can be divided into three stages (Figure 5). As temperature figure homogeneous co-blending. The thermal decomposition mass of MOF uniformly distributed in the matrix is represented by the $5-10 \%$ mass difference. All prepared membranes can be used in normal environments and can withstand a temperature range of $0-480^{\circ} \mathrm{C}$.

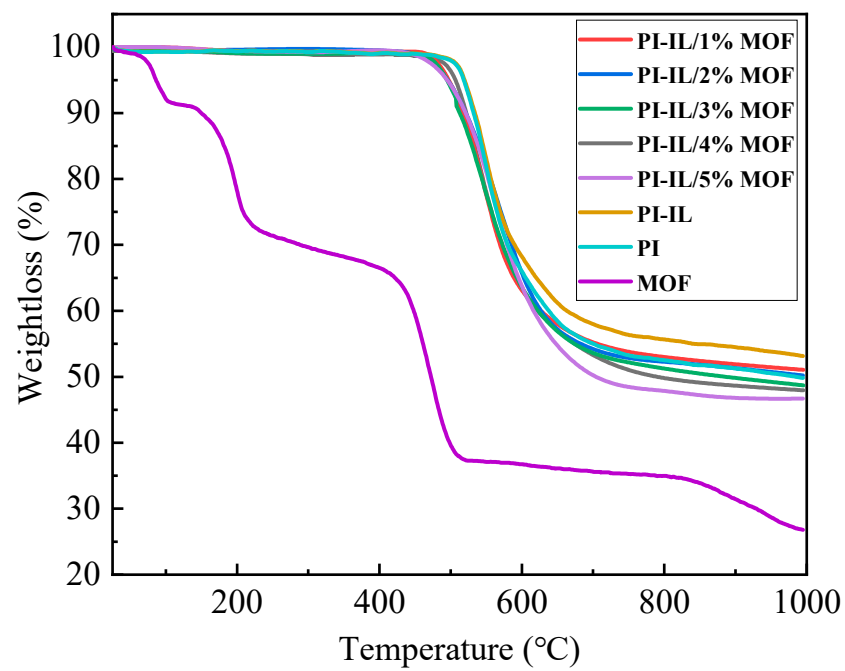

Figure 5. TGA curve of MOF, PI, PI-IL and PI-IL/x\% MOF membranes. 


\subsection{Gas Permeation Performance of the MMMs}

The prepared PI-IL/ $\mathrm{x} \% \mathrm{MOF}$ membranes were tested for the separation performance of $\mathrm{CO}_{2}$ and $\mathrm{CH}_{4}$ mixed gas at a 1:1 ratio. Table 3 shows the gas separation performance of membranes. When PI was capped with IL, the membrane's permeability increased to 5.19 Barrer and 74.15, which was 4.36 and 6.21-times that of pure PI membranes, respectively. The addition of ionic liquid increased $\mathrm{CO}_{2}$ permeability and $\mathrm{CO}_{2} / \mathrm{CH}_{4}$ selectivity of the PI membrane. This phenomenon was most likely due to the affinity of ionic liquid for $\mathrm{CO}_{2}$. The ionic liquid's imidazole groups can interact with $\mathrm{CO}_{2}$ to enhance $\mathrm{CO}_{2}$ adsorption; consequently, the PI-IL membrane achieved higher $\mathrm{CO}_{2}$ permeability. It is also hypothesized that the effect of ionic liquid on gas permeability is partly due to the plasticizing effect of ionic liquids on polymers. The addition of ionic liquids to polymer membranes reduces glass transition temperature, while increasing chain mobility resulted in higher permeability [38]. Meanwhile, inorganic anions $\left(\mathrm{BF}_{4}, \mathrm{NO}_{3}\right.$ and $\left.\mathrm{Cl}\right)$ had a distinctive effect on its $\mathrm{CO}_{2}$ sorption properties. Overall, it was concluded that increasing the basicity of anions is known to enhance $\mathrm{CO}_{2}$ sorption [39]. The effect of IL in membranes is to increase their $\mathrm{CO}_{2}$ solubility while decreasing $\mathrm{CH}_{4}$ solubility [40]. As shown in Table 4, the solubility coefficient of the membrane increased after adding ionic liquid and MOF. In summary, the addition of IL increases the separation effect of $\mathrm{CO}_{2} / \mathrm{CH}_{4}$.

Table 3. $\mathrm{CO}_{2}$ and $\mathrm{CH}_{4}$ of permeability and selectivity of membranes measured at $34{ }^{\circ} \mathrm{C}$.

\begin{tabular}{ccccc}
\hline No. & Sample & $\mathbf{P C O}_{2} / \mathbf{B a r}^{\mathbf{a}}$ & $\mathbf{P C H}_{\mathbf{4}} / \mathbf{B a r}^{\mathbf{a}}$ & $\mathbf{P C O}_{\mathbf{2}} / \mathbf{P C H}_{\mathbf{4}}$ \\
\hline 1 & PI & 1.19 & 0.10 & 11.93 \\
2 & PI-IL & 5.19 & 0.07 & 74.15 \\
3 & PI-IL/1\% MOF & 5.57 & 0.07 & 79.53 \\
4 & PI-IL/2\% MOF & 6.21 & 0.07 & 88.74 \\
5 & PI-IL/3\% MOF & 7.61 & 0.08 & 95.10 \\
6 & PI-IL/4\% MOF & 6.49 & 0.09 & 72.13 \\
7 & PI-IL/5\% MOF & 4.01 & 0.08 & 50.08 \\
\hline Note: $^{\text {a }}$ 1 Barrer $=10^{-10} \mathrm{~cm}^{3}$ (STP) $\mathrm{cm} \mathrm{cm}^{-2} \mathrm{~s}^{-1} \mathrm{cmHg}^{-1}$. &
\end{tabular}

Note: ${ }^{\text {a }} 1$ Barrer $=10^{-10} \mathrm{~cm}^{3}(\mathrm{STP}) \mathrm{cm} \mathrm{cm}^{-2} \mathrm{~s}^{-1} \mathrm{cmHg}^{-1}$.

Table 4. $\mathrm{CO}_{2}$ and $\mathrm{CH}_{4}$ solubility and diffusivity coefficients of membranes measured at $34{ }^{\circ} \mathrm{C}$.

\begin{tabular}{|c|c|c|c|c|c|}
\hline No. & Sample & $\mathrm{DCO}_{2}\left(\mathrm{~cm}^{2} \mathrm{~s}^{-1}\right)$ & $\mathrm{SCO}_{2}\left(\mathrm{~cm}^{3}(\mathrm{STP}) \mathrm{cm}^{2} \cdot \mathrm{cmHg}\right)$ & $\mathrm{DCH}_{4}\left(\mathrm{~cm}^{2} \mathrm{~s}^{-1}\right)$ & $\mathrm{SCH}_{4}\left(\mathrm{~cm}^{3}(\mathrm{STP}) \mathrm{cm}^{2} \cdot \mathrm{cmHg}\right)$ \\
\hline 1 & PI & $2.33 \times 10^{-6}$ & $0.51 \times 10^{-4}$ & $2.78 \times 10^{-5}$ & $3.6 \times 10^{-7}$ \\
\hline 2 & PI-IL & $3.02 \times 10^{-6}$ & $1.72 \times 10^{-4}$ & $3.62 \times 10^{-5}$ & $1.93 \times 10^{-7}$ \\
\hline 3 & PI-IL/1\% MOF & $2.72 \times 10^{-6}$ & $2.05 \times 10^{-4}$ & $3.79 \times 10^{-5}$ & $1.85 \times 10^{-7}$ \\
\hline 4 & PI-IL $/ 2 \%$ MOF & $2.74 \times 10^{-6}$ & $2.27 \times 10^{-4}$ & $3.90 \times 10^{-5}$ & $1.79 \times 10^{-7}$ \\
\hline 5 & PI-IL/3\% MOF & $3.02 \times 10^{-6}$ & $2.52 \times 10^{-4}$ & $4.09 \times 10^{-5}$ & $1.96 \times 10^{-7}$ \\
\hline 6 & $\mathrm{PI}-\mathrm{IL} / 4 \% \mathrm{MOF}$ & $2.82 \times 10^{-6}$ & $2.30 \times 10^{-4}$ & $3.95 \times 10^{-5}$ & $2.28 \times 10^{-7}$ \\
\hline 7 & $\mathrm{PI}-\mathrm{IL} / 5 \% \mathrm{MOF}$ & $2.24 \times 10^{-6}$ & $1.79 \times 10^{-4}$ & $3.52 \times 10^{-5}$ & $2.27 \times 10^{-7}$ \\
\hline
\end{tabular}

As shown in Table 3, introducing UiO-66- $\mathrm{NH}_{2}$ particles to PI-IL/x\% MOF mixed matrix membranes clearly enhanced their gas permeability properties. The permeability of PI-IL/3\% MOF was the highest with a value 7.61 Barrer. This behavior may be due to the addition of porous $\mathrm{UiO}-66-\mathrm{NH}_{2}$ particles, which improves the transport passage of gas through the membrane and provides a higher affinity of $\mathrm{UiO}-66-\mathrm{NH}_{2}$ for $\mathrm{CO}_{2}$ than $\mathrm{CH}_{4}$. The selectivity of $\mathrm{CO}_{2} / \mathrm{CH}_{4}$ increased to 95.10 when $\mathrm{UiO}-66-\mathrm{NH}_{2}$ loading content was 3\%; this could be ascribed to the molecular sieving effect of $\mathrm{UiO}-66-\mathrm{NH}_{2}$ nanoparticles [41]. As the loading content increased to $4 \%$ and $5 \%$, the selectivities dropped compared to the PI-IL/3\% MOF membrane but remained higher than the pure PI membrane. These values might be attributed to a smaller degree of agglomeration of MOF particles in the matrix, blocking a small part of gas transfer. Meanwhile, the presence of MOF seems to rigidify polymeric chains; therefore, the rigidified polymeric chains around the MOF and polyimide surfaces may be one of the causes for permeability reduction. Other possibilities for the 
decline in selectivities include partial pore blockage of MOF by polymer chains [42]. In the case of PI-IL/1-3\% MOF MMMs, the results show that the presence of IL increases the adhesion of UiO-66- $\mathrm{NH}_{2}$ in MMMs, since IL can also act as a wetting agent for UiO-66$\mathrm{NH}_{2}$ [43]. On the other hand, IL may enhance interfacial interaction via plasticization; the presence of IL in PI-IL/1-3\% MMMs improves gas separation performance.

The Robeson upper bound of PI, PI-IL and PI-IL/ $\mathrm{x} \%$ MOF membranes for the gas pair of $\mathrm{CO}_{2} / \mathrm{CH}_{4}$ is plotted in Figure 6. The PI-IL membrane exhibits higher $\mathrm{CO}_{2}$ permeability and permselectivity compared to pure PI membrane, for which its plot moves up on Robeson's 1991 upper bound. $\mathrm{CO}_{2}$ and $\mathrm{CH}_{4}$ permselectivities of PI-IL/x\% MOF mixed matrix membrane were higher than those of the PI-IL membrane, and gas separation data approaches Robeson's 2008 upper bound when UiO-66- $\mathrm{NH}_{2}$ filler loading content reaches $1-2 \%$. PI-IL filled with UiO-66- $\mathrm{NH}_{2}$ at 4 and $5 \%$ exhibit lower permselectivities than the PI-IL membrane, but it is still higher than the 1991 upper bound. In summary, this increase in permselectivity confirmed that the introduction of IL and UiO-66- $\mathrm{NH}_{2}$ can enhance gas separation performance of the fabricated membranes.

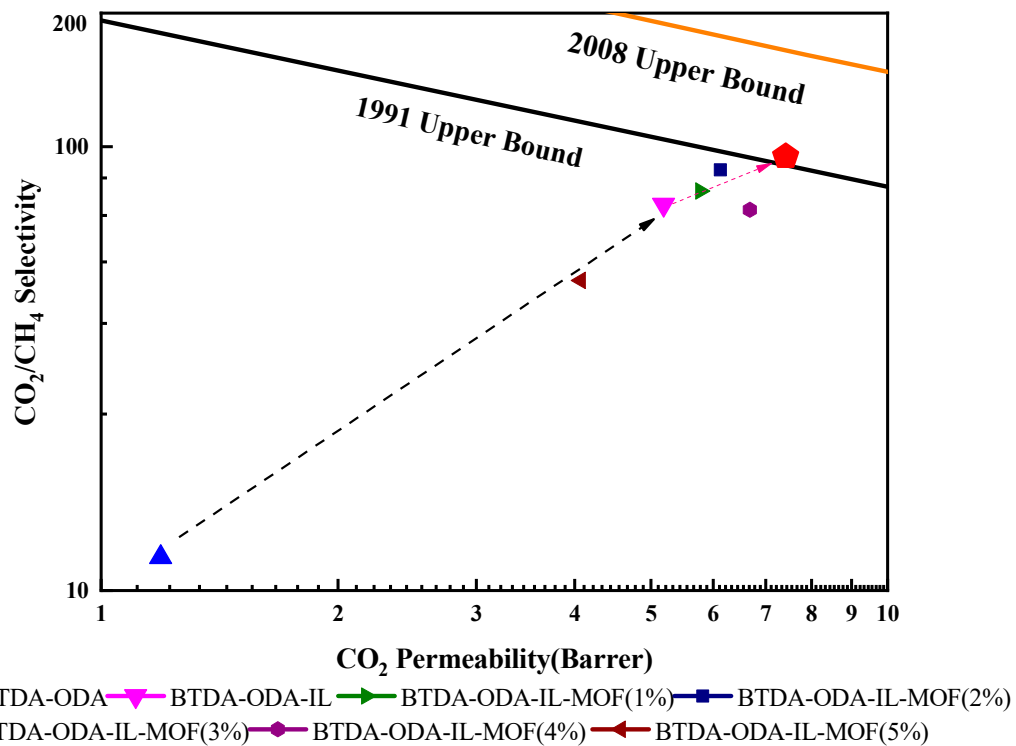

Figure 6. $\mathrm{CO}_{2} / \mathrm{CH}_{4}$ separation performance of MMMs and comparison with 1991 Robeson upper bound and 2008 Robeson upper bound.

\section{Conclusions}

In conclusion, $\mathrm{UiO}-66-\mathrm{NH}_{2}$ particles were used to improve $\mathrm{CO}_{2}$ gas permselectivity in an ionic liquid capped polyimide matrix. IL was selected to enhance the permeability of a polyimide. All the obtained mixed matrix membranes exhibited excellent mechanical and thermal properties, allowing them to meet conventional conditions of membranes. More importantly, $\mathrm{CO}_{2}$ permeability and selectivity of $\mathrm{MMM}$ exhibited an obvious improvement over PI-IL. The mixed matrix membranes capped by IL and blended with UiO-66- $\mathrm{NH}_{2}$ provide an efficient method to improve $\mathrm{CO}_{2}$ selectivity while retaining gas permeability.

Supplementary Materials: The following supporting information can be downloaded at: https: / / www.mdpi.com/article/10.3390/membranes12010034/s1, Figure S1: FT-IR spectrum of IL, PI, PI-IL; Figure S2: The surface topography of PI-IL/1\%-5\%MOF MMMs (a-e).

Author Contributions: Original draft preparation, experimental and characterization: Y.Z. Writingreview and editing: H.J. Financial support: Q.W., G.S. and G.Y. Assistance in membrane characterization: W.M., S.X., M.Z., Y.Q., P.J. and S.L. All authors have read and agreed to the published version of the manuscript. 
Funding: Financial and facility support for this research came from Key research and development guidance projects in Heilongjiang province (No. GZ20210034) and The Fundamental Research Funds in Heilongjiang Provincial Universities (No. 135309503).

Institutional Review Board Statement: Not applicable.

Informed Consent Statement: Not applicable.

Data Availability Statement: Not applicable.

Acknowledgments: This work was supported by the Key research and development guidance projects in Heilongjiang Province (GZ20210034), Heilongjiang Provincial Leading Talent Echelon Infrastructure funds (2019-278), China, and The Fundamental Research Funds in Heilongiiang Provincial Universities (No. 135309503).

Conflicts of Interest: The authors declare that they have no known competing financial interests or personal relationships that could have appeared to influence the work reported in this paper.

\section{References}

1. Michael, T. Publikationen. Energy Technology Perspectives 2010: Scenarios and Strategies to 2050; International Energy Agency: Paris, France, 2010.

2. Pratibha, P.; Chauhan, R.S. Memranes for gas separation. Prog. Polym. Sci. 2001, 26, 853-893. [CrossRef]

3. Galizia, M.; Chi, W.S.; Smith, Z.P.; Merkel, T.C.; Baker, R.W.; Freeman, B.D. 50th anniversary perspective: Polymers and mixed matrix membranes for gas and vapor separation: A review and prospective opportunities. Macromolecules 2017, 50, 7809-7843. [CrossRef]

4. Basu, S.; Khan, A.L.; Angels, C.O.; Liu, C.; Vankelecom, I.F.J. Membrane-based technologies for biogas separations. Chem. Soc. Rev. 2010, 39, 750-768. [CrossRef] [PubMed]

5. Xu, S.; Ma, W.; Zhou, H.; Zhang, Y.; Jia, H.; Xu, J.; Jiang, P.; Wang, X.; Zhao, W. Preparation of butadiene-bridged polymethylsiloxane (BBPMS)/ethyl cellulose(EC) hybrid membranes for gas separation. Eur. Polym. J. 2021, 157, 110679. [CrossRef]

6. Zulhairun, A.K.; Fachrurrazi, Z.G.; Izwanne, M.N.; Ismail, A.F. Asymmetric hollow fiber membrane coated with polydimethylsiloxanemetal organic framework hybrid layer for gas separation. Sep. Purif. Technol. 2015, 146, 85-93. [CrossRef]

7. Zulhairun, A.K.; Ng, B.C.; Ismail, A.F.; Murali, R.S.; Abdullah, M.S. Production of Mixed Matrix Hollow Fiber Membrane for $\mathrm{CO}_{2} / \mathrm{CH}_{4}$ separation. Sep. Purif. Technol. 2014, 137, 1-12. [CrossRef]

8. Zulhairun, A.K.; Ismail, A.F.; Matsuura, T.; Abdullah, M.S.; Mustafa, A. Asymmetric mixed matrix membrane incorporating organically modified clay particle for gas separation. Chem. Eng. J. 2014, 241, 495-503. [CrossRef]

9. Liu, Y.; Wang, N.Y.; Caro, J. In situ formation of LDH membranes of different microstructures with molecular sieve gas selectivity. J. Mater. Chem. A 2014, 2, 5716-5723. [CrossRef]

10. Liu, Y.; Pan, J.; Wang, N.; Steinbach, F.; Liu, X.; Caro, J. Remarkably Enhanced Gas Separation by Partial Self-Conversion of a Laminated Membrane to Metal-Organic Frameworks. Angew. Chem. 2015, 127, 3071-3075. [CrossRef]

11. Nafisi, V.; Hagg, M.B. Gas separation properties of ZIF-8/6FDA-durene diamine mixed matrix membrane. Sep. Purif. Technol. 2014, 128, 31-38. [CrossRef]

12. Ghanem, A.S.; Shammakh, M.B.; Usman, M.; Khan, M.F.; Dafallah, H.; Mohamed, A.M. High gas permselectivity in ZIF302/polyimide self-consistent mixed matrix membrane. J. Appl. Polym. Sci. 2019, 137, 48513. [CrossRef]

13. Yu, G.; Zou, X.; Sun, L.; Liu, B.; Wang, Z.; Zhang, P.; Zhu, G. Constructing Connected Paths between UiO-66 and PIM-1 to Improve Membrane $\mathrm{CO}_{2}$ Separation with Crystal-Like Gas Selectivity. Adv. Mater. 2019, 31, 1806853. [CrossRef]

14. Kandian, M.; Nilsen, M.H.; Usseglio, S.; Jakobsen, S.; Olsbye, U.; Tilset, M.; Larabi, C.; Quadrelli, E.A.; Bonino, F.; Lillerud, K.P. Synthesis and Stability of Tagged UiO-66 Zr-MOFs. Chem. Mat. 2010, 22, 6632-6640. [CrossRef]

15. Wang, H.; He, S.; Qin, X.; Li, C.; Li, T. Interfacial engineering in metal-organic framework-based mixed matrix membranes using covalently grafted polyimide brushes. J. Am. Chem. Soc. 2018, 140, 17203-17210. [CrossRef] [PubMed]

16. Robeson, L.M. Correlation of separation factor versus permeability for polymeric membranes. J. Membr. Sci. 1991, 62, 165-185. [CrossRef]

17. Robeson, L.M. The upper bound revisited. J. Membr. Sci. 2008, 320, 390-400. [CrossRef]

18. Calle, M.; Jo, H.J.; Doherty, C.M.; Hill, A.J.; Lee, Y.M. Cross-linked thermally rearranged poly(benzoxazole-co-imide) membranes prepared from ortho-hydroxycopolyimides containing pendant carboxyl groups and gas separation properties. Macromolecules 2015, 48, 2603-2613. [CrossRef]

19. Zhuang, Y.B.; Seong, J.G.; Lee, W.H.; Do, Y.S.; Lee, M.J.; Wang, G.; Guiver, M.D.; Lee, Y.M. Mechanically tough, thermally rearranged (TR) random/block poly(benzoxazole-co-imide) gas separation membrane. Macromolecules 2015, 48, 5286-5299. [CrossRef]

20. Xu, S.P.; Zhou, H.L.; Jia, H.G.; Xu, J.Y.; Ma, L.Q.; Zang, Y.; Jiang, P.F.; Ma, W.Q.; Zhang, Y.S.; Zhao, W.W.; et al. Preparation and high performance of cellulose acetate films by grafting with imidazole ionic liquid. ACS Omega 2020, 6, 12500-12506. [CrossRef] [PubMed]

21. Yaghi, O.M.; Li, G.; Li, H. Selective binding and removal of guests in a microporous metal-organic framework. Nature 1995, 378, 703-706. [CrossRef] 
22. Denny, J.M.S.; Moreton, J.C.; Benz, L.; Cohen, S.M. Metal-organic frameworks for membrane-based separations. Nat. Rev. Mater. 2016, 1, 16078. [CrossRef]

23. Hou, J.M.; Wei, Y.Y.; Zhou, S.; Wang, Y.J.; Wang, H.H. Highly efficient $\mathrm{H}_{2} / \mathrm{CO}_{2}$ separation via an ultrathin metal-organic framework membrane. Chem. Eng. Sci. 2018, 182, 180-188. [CrossRef]

24. Bernabe, D.P.; Caparanga, A.R.; Hu, C.C.; You, S.J.; Lee, K.R.; Lai, J.Y. Microporous Aluminum Fumarate (A520) Metal-Organic Framework as modifier to free-standing mixed matrix membrane. Mater. Sci. Forum 2018, 934, 170-175. [CrossRef]

25. Bernabe, D.P.; Caparanga, A.R.; Hu, C.C.; You, S.J.; Lee, K.R.; Lai, J.Y. MOF-modified high permeability polyimide membrane for gas separation. Key Eng. Mater. 2019, 801, 313-318. [CrossRef]

26. Liu, B.; Li, D.; Yao, J.; Sun, H. Improved $\mathrm{CO}_{2}$ separation performance and interfacial affinity of mixed matrix membrane by incorporating UiO-66-PEI@[bmim][Tf2N] particles. Sep. Purif. Technol. 2020, 239, 116519. [CrossRef]

27. Erucar, I.; Keskin, S. Screening Metal-organic framework-based mixed-matrix membranes for $\mathrm{CO}_{2} / \mathrm{CH}_{4}$ separations. Ind. Eng. Chem. Res. 2011, 50, 12606-12616. [CrossRef]

28. Baker, R.W. Future directions of membrane gas separation technology. Ind. Eng. Chem. Res. 2002, 41, 1393-1411. [CrossRef]

29. Zhang, X.M.; Xiong, W.J.; Tu, Z.H.; Peng, L.L.; Hu, X.B. Supported ionic liquid membranes with dual-site interaction mechanism for efficient separation of $\mathrm{CO}_{2}$. ACS Sustain. Chem. Eng. 2019, 7, 10792-10799. [CrossRef]

30. Nikolaeva, D.; Azcune, I.; Tanczyk, M.; Warmuzinski, K.; Jaschik, M.; Sandru, M.; Dahl, P.I.; Genua, A.; Los, S.; Sheridan, E. The performance of affordable and stable cellulose-based poly-ionic membranes in $\mathrm{CO}_{2} / \mathrm{N}_{2}$ and $\mathrm{CO}_{2} / \mathrm{CH}_{4}$ gas separation. J. Membr. Sci. 2018, 564, 552-561. [CrossRef]

31. Nik, O.G.; Chen, X.Y.; Kaliaguine, S. Functionalized metal organic framework-polyimide mixed matrix membranes for $\mathrm{CO}_{2} / \mathrm{CH}_{4}$ separation. J. Membr. Sci. 2012, 413, 48-61. [CrossRef]

32. Sarmadi, R.; Salimi, M.; Pirouzfar, V. The assessment of honeycomb structure UiO-66 and amino functionalized UiO-66 metalorganic frameworks to modify the morphology and performance of Pebax®1657-based gas separation membranes for $\mathrm{CO}_{2}$ capture applications. Environ. Sci. Pollut. Res. 2020, 27, 40618-40632. [CrossRef]

33. Azizi, N.; Mohammadi, T.; Behbahani, R.Z. Comparison of permeability performance of PEBAX-1074/TiO 2 , PEBAX-1074/SiO 2 and PEBAX-1074/ $\mathrm{Al}_{2} \mathrm{O}_{3}$ nanocomposite membranes for $\mathrm{CO}_{2} / \mathrm{CH}_{4}$ Separation. Chem. Eng. Res. Des. 2017, 117, 177-189. [CrossRef]

34. Fragaa, S.; Monteleoneb, M.; Lanc, M.; Esposito, E.; Fuoco, A.; Giorno, L.; Pilnacek, K.; Friess, K.; Carta, M.; McKeown, N.C.; et al. A novel time lag method for the analysis of mixed gas diffffusion in polymeric membranes by on-line mass spectrometry: Method development and validation. J. Membr. Sci. 2018, 561, 39-58. [CrossRef]

35. Taddei, M.; Dau, P.V.; Cohen, S.M.; Ranocchiari, M.; Bokhoven, J.A.V.; Costantino, F.; Sabatini, S.; Vivani, R. Efficient microwave assisted synthesis of metal-organic framework UiO-66: Optimization and scale up. Dalton Trans. 2015, 44, 14019-14026. [CrossRef]

36. Garibay, S.J.; Cohen, S.M. Isoreticular synthesis and modifification of frameworks with the UiO-66 topology. Chem. Commun. 2010, 46, 7700-7702. [CrossRef] [PubMed]

37. Jiang, P.; Jia, H.; Xu, J.; Zhou, H.; Zhang, M.; Xu, S.; Zang, Y.; Zhang, X.; Zhang, Y. Preparation of high-strength polyimide membranes capped by ionic liquids. High Perform. Polym. 2020, 33, 568-575. [CrossRef]

38. Lang, L.Z.; Gan, Q.; Nancarrow, P. Composite ionic liquid and polymer membranes for gas separation at elevated temperatures. J. Membr. Sci. 2014, 450, 407-417. [CrossRef]

39. Zhang, M.X.; Yu, A.; Wu, X.Y.; Shao, P.P.; Huang, X.; Ma, D.; Han, X.H.; Xie, J.; Feng, X.; Wang, B. Sealing functional ionic liquids in conjugated microporous polymer membrane by solvent-assisted micropore tightening. Nano Res. 2021, 7, 1-6. [CrossRef]

40. Wang, C.; Luo, X.; Luo, H.; Jiang, D.E.; Li, H.; Dai, S. Tuning the Basicity of Ionic Liquids for Equimolar CO 2 Capture. Angew. Chem. Int. Ed. 2011, 50, 4918-4922. [CrossRef]

41. Shi, Y.P.; Wu, S.S.; Wang, Z.G.; Bi, X.Y.; Huang, M.H.; Zhang, Y.T.; Jina, J. Mixed matrix membranes with highly dispersed MOF nanoparticles for improved gas separation. Sep. Purif. Technol. 2021, 277, 119449. [CrossRef]

42. Li, Y.; Chuang, T.; Cao, C.; Kulprathipanja, S. The effects of polymer chain rigidifification, zeolite pore size and pore blockage on polyethersulfone (PES)-zeolite A mixed matrix membranes. J. Membr. Sci. 2005, 260, 45-55. [CrossRef]

43. Hudiono, Y.C.; Carlisle, T.K.; LaFrate, A.L.; Gin, D.L.; Noble, R.D. Novel mixed matrix membranes based on polymerizable room-temperature ionic liquids and SAPO-34 particles to improve $\mathrm{CO}_{2}$ separation. J. Membr. Sci. 2011, 370, 141-148. [CrossRef] 